\title{
Relationships between growth, survival, physiology and behaviour - A multi-criteria approach to Haliotis tuberculata phenotypic traits
}

\author{
Lachambre Sébastien ${ }^{1,2}$, Huchette Sylvain ${ }^{2}$, Day Rob ${ }^{3}$, Boudry Pierre ${ }^{4}$, Rio-Cabello Antoine ${ }^{1}$, \\ Fustec Timothée ${ }^{5}$, Roussel Sabine ${ }^{1,{ }^{*}}$
}

${ }^{1}$ Univ Brest, CNRS, IRD, Ifremer, LEMAR, IUEM, 29280 Plouzané, France

${ }^{2}$ France Haliotis, 29880 Plouguerneau, France

${ }^{3}$ Department of Zoology, Parkville, Melbourne University, Victoria 3010, Australia

4 Ifremer, Univ Brest, CNRS, IRD, LEMAR, IUEM, 29280 Plouzané, France

${ }^{5}$ Institut Supérieur d'Agriculture, 48 boulevard Vauban, 59046 Lille, France

*Corresponding author : Sabine Roussel, email address : Sabine.Roussel@univ-brest.fr

\begin{abstract}
:
Abalone growth rate is often identified among important traits to improve through selective breeding. However, the rapid success of some selective breeding plans has sometimes led to negative effects in some aquaculture species due to trade-offs. One of them is the loss of homeostasis of selected animals which results in the inability to resist the stress experienced during the rearing process. In this context, this study aimed to analyze the phenotypic relationships between growth, and physiological and behavioural traits in Haliotis tuberculata under stressful conditions. Eleven traits related to growth, immunity, reproduction and behaviour were recorded under laboratory conditions. A total of 120 adults from wild or farm origin were first monitored during a 3-week stress period (high density and acute stress handling) during winter, followed by 6 months on-growing in sea-cages. Relationships between parameters were analyzed using a multi-factorial approach. Wild and farm stocks could only be discriminated on behaviour traits, confirming that the French abalone industry is in the beginning of the domestication process. After 3 weeks of chronic stress, the righting latency of an abalone was linked to better survival and faster growth. Abalones having the best growth after 6 months were characterized by higher activity during the previous winter period, whereas an early gonad maturation reduced the growth in summer. Our results provide a basis for the establishment of a multi-trait breeding program to improve the growth rate while controlling the evolution of physiological and behavioural traits.
\end{abstract}

Statement of relevance

The relationships of behavioural and physiological variables with survival and weight gain after application of important stressors were studied in order to provide a better understanding of Haliotis tuberculata biology during early domestication stage. This paper will give information on new targets and tools for selective breeding. 


\section{Abbreviations}

- ANOVA, Analysis of Variance;

- PCA, Principal Component Analysis;

- SEM, Standard Error of the Mean

Keywords : Haliotis tuberculata, Growth, Behaviour, Physiology, Multivariate analysis, Phenotyping 


\section{Introduction}

Abalone (Haliotis sp.) have been consumed in Asia for centuries as a part of traditional food and are currently consumed in many countries (Elliott, 2000). Worldwide demand has exceeded its supply. This has resulted in an excessive pressure on the stocks in many fisheries (Gordon and Cook, 2004) and a global decrease of the wild stocks (Huchette and Clavier, 2004). The high market value of abalone has allowed an impressive development of aquaculture production throughout the world in the last two decades (Lucas et al., 2006). The success of abalone production is often consolidated by selective breeding plans that generate production gains (Camara and Symonds, 2014; Elliott, 2000).

Haliotis tuberculata is a European species that has been brought into aquaculture in the 2000s. This gastropod is nocturnal and grazes macro-algae found on the rock or drifting algae. It is a slow growing abalone: four years are necessary to reach a commercial size of 7-8 cm (Huchette and Clavier, 2004). The European abalone Haliotis tuberculata is a species sensitive to environmental changes (Cenni et al., 2010). H. tuberculata is gonochoric and starts its maturation at the end of winter in Brittany and is fully mature in the (Travers, 2008). No genetic improvements have yet been obtained through selective breeding or chromosome manipulations. This European industry would benefit from similar gains to those obtained for other abalone species worldwide (Rhode et al., 2012). However, in many animal production systems, individuals submitted to high productivity improvement seem to be more at risk from behavioural, physiological and immunological issues (Rauw et al., 1998). To avoid that, 
the current selective breeding strategy is to more carefully define the trait to improve (Camara and Symonds, 2014; Elliott, 2008) and to have a multi-criteria approach, adding physiological, behavioural and metabolic traits to complement production traits (Camara and Symonds, 2014; Rauw et al., 1998). This methodology is used in agricultural production but requires a good biological knowledge and efficient phenotyping methodologies (Monget and Le Bail, 2009).

Domestication is a "long process by which a population of animals becomes dependent on and adapted to humans and to a captive environment by some combination of genetic changes occurring over generations and environmentally induced by events reoccurring in each generation" (Price, 1984). During the domestication process, animals are bred in captivity and encounter several stressors related to captivity environment such as high density or suboptimal conditions. The culture environment reduces the pressure of natural selection to adapt on many traits, but introduces new pressures on other traits (Lorenzen et al., 2012). Abalone is a sensitive species to stressors (Hooper et al., 2011; Travers, 2008; Travers et al., 2008a). High density (Huchette et al., 2003), high ammonia concentration (Cheng et al., 2004a), high temperature and heat shock (Cheng et al., 2004b; Hooper et al., 2014), manipulation (Hooper et al., 2011) and shaking (Malham et al., 2003) are well identified farm stressors that affect the abalone immune system and increase the diseases susceptibility to pathogens. Thus after a period of domestication, captive 'type' abalone might be already more adapted to the culture environment (Lorenzen et al., 2012).

All these previous studies emphasized the importance of linking farm stressors and husbandry practices to animal biology in order to understand growth and mortalities in farms. A biometric study has already been performed on $H$. tuberculata indicating that length, width, 
weight, meat yield and gonad weight ratio as well as different growth parameters are highly correlated (Basuyaux, 1997). In addition, an immune screening profile was also carried out on H. tuberculata (Travers et al., 2008c). For abalone, among many immune parameters, the phagocytosis efficiency (Hooper et al., 2007; Travers et al., 2008b; Travers et al., 2008c) seemed to be a key parameter to predict survival in a rearing system. . A diminution of phagocytosis efficiency is often induced by manipulation and environmental condition changes. In addition, study has shown a relation between disease susceptibility and gonadic development (Travers et al., 2008a).

In complement to physiology, behavioural observations are also a useful tool to evaluate an animal's adaptation to an aquaculture rearing system (Claireaux et al., 2015; Millot et al., 2010; Robinson et al., 2013). The righting test, which consists of measuring the time needed for an abalone to fully complete a righting movement after it has been placed upside down was used as a non-invasive tool to provide an evaluation of the energetic reserve of an abalone (Baldwin et al., 2007). Abalone species are generally sedentary, for example $H$. iris spend less than $6 \%$ of their time moving (Allen et al., 2006). H. tuberculata is characterized by two patterns of behaviour: "wanderer" abalone move and occupy hides, showing a more pronounced homing behaviour than "sedentary" abalone (Cenni et al., 2009). More movements were also observed during the 24 hours following an acute stress (Robinson et al., 2013). In addition, this locomotion is negatively correlated with food availability (Allen et al., 2006).

This study presents a screening of the Haliotis tuberculata biology under farm stressors. The first aim was to describe production, physiological and behavioural traits of $H$. tuberculata comparing wild and unselected farm stocks. The second aim was to understand 
which behavioural and physiological traits were related to growth and survival capacity in stressful conditions, using multivariate analysis. 


\section{Materials and Methods}

\subsection{Animals}

Farmed adult $H$. tuberculata $(\mathrm{n}=60$ abalone in total, $68 \pm 4.0 \mathrm{~mm}$ total shell length, 3.5 years old) were sampled randomly from 9 sea-based breeding structures of the France Haliotis abalone farm $\left(48^{\circ} 36^{\prime} 46 \mathrm{~N} ; 4^{\circ} 33^{\prime} 30 \mathrm{~W}\right.$, Plouguerneau, France) in winter. This farm started in 2004. The France Haliotis stocks resulted from systematic mating between wild and farmed broodstock, mainly to avoid inbreeding. Wild adult $H$. tuberculata $(\mathrm{n}=60$ abalone in total, 71 $\pm 4.0 \mathrm{~mm}$ total shell length, age unknown) were also collected the same day by diving in two areas next to the cages, separated from them with at least $100 \mathrm{~m}$ of sandy bottom. In addition, farmed stocks could be easily identified with the green coloration at the apex, distinctive of juvenile feed with Ulvella lens in France Haliotis hatchery. Both farmed and wild abalone were placed in bags containing circular black plastic oyster seed collectors (diameter: 140 $\mathrm{mm}$ ) and transported to the land-based laboratory. They were placed in experimental tanks for 3 weeks before transferring them to sea-growing structure for 6 months.

\subsection{Experimental set-up}

The experimental tanks were 4 grey flat sub-square epoxy painted fibreglass tanks $(1.1 \mathrm{x} 1.1 \mathrm{x}$ $0.20 \mathrm{~m}$, water volume $=100 \mathrm{~L}$ ) with rough plastic strips on the edges to prevent escape. Each tank was supplied with 75 L.h-1 of $3 \mu \mathrm{m}$ mechanically filtered seawater (average $10 \pm 1^{\circ} \mathrm{C}$ ) and an aeration system was placed in each tank. Ten pairs of oyster seed collectors were uniformly distributed along the tank edges to be used as hiding places. The light dark regime was adjusted to the seasonal rhythm 10:14h (Light from 08:30 to 18:30). To avoid stressful conditions during light changes, 30 minute dawn (8:00 to 8:30) and dusk (18:30 to 19:00) transitions were regulated using a dimmer (Gold Star, Besser Elektronik, Italia). Tanks were cleaned twice a week using a hose and $25 \mu \mathrm{m}$ filters changed every day. The algae Palmaria 
palmata, Saccharina latissima, Laminaria digitata and Ulva lactuca were placed ad libitum in plastic boxes in the middle of the tank. All tanks were continuously videotaped with 4 digital cameras (TS-WD6001HPSC, Sygonix Gmbh, Germany), linked to a $24 \mathrm{~h}$ recording device (TVVR 40021, Abus, Germany). The righting tests were video-recorded for 4 min with a camcorder (Sony, HDR-XR155)

The sea-based growing experiment took place in Allibert. The growing structure was composed of 4 square compartments $(1 \mathrm{~m} * 1.2 \mathrm{~m} * 0.5 \mathrm{~m})$ designed for abalone rearing. Each compartment contained 10 rows of 41 black plastic oyster collectors. Abalones were fed once a month with Laminaria digitata, distributed ad libitum in the compartment.

\subsection{Experimental design}

Behavioural and physiological measurements were performed in the laboratory from the end of December 2013 to February 2014 with 3 repetitions. For each repetition, 2 tanks containing farmed abalone and 2 tanks containing wild abalone ( $\mathrm{n}=10$ abalone per tank) were used. After gently detaching the abalone with a spatula from the transport collectors, length and weight were measured and abalone were individually marked with a reflective tag and a numbered plastic tag attached with cyanoacrylate glue to their shell (Shepherd, 1988) before they were placed in the experimental tank.

Observations were made during three stress periods that were imposed in the experimental tanks, corresponding to three stressors regularly experienced during husbandry procedures:

- Habituation period (Day 1 to 7) corresponded to the period of recovery from transport and handling. This is considered a mild stress. Previous observations have shown that the shipping stress and the tagging stress have no impacts after 3 days (Hooper et al., 2011). 
- Over-density period (Day 8 to 15): 52 additional abalones were added day 8 in order to induce a high-density stress $\left(62\right.$ abalone $\left./ \mathrm{m}^{2}\right)$. The 52 non-experimental abalone were removed day 15 .

- Post-acute stress period (Day 15 to 21): on day 15, abalone were detached and shaken for $20 \mathrm{~min}$ in air, which is a common stressor experienced by abalone during the screening process on farms (Hooper et al., 2011). After 1 hour in air, they were returned to their tank. After the stress, the abalones were left undisturbed until day 21. The phagocytosis measurement and righting tests were performed on day 21 in order to evaluate the basal immunological status and behavioural response before returning to the sea-structures. A 5-day period is enough to get a return to phagocytosis basal situation after an acute stress (Hooper et al., 2011).

After the laboratory stress measurements ( $\mathrm{T} 0=$ beginning of the growth period), abalone were placed in the sea growing structure with a low density $\left(5\right.$ abalone $\left./ \mathrm{m}^{2}\right)$ for $2-3$ months. The T0 is specific of the repetition (T0 ofrepetition 1 : end of December; T0 of repetition 2 : middle of January; T0 of repetition 3: beginning of February). In April (T3 = 2-3 growth months achieved), the sea-growing structure was brought to the farm. Abalone were gently detached. Weight, length, visual gonad index and survival were determined for each abalone before they were returned to the standard rearing density $\left(50\right.$ abalone $\left./ \mathrm{m}^{2}\right)$ in the sea-growing structure. In June (T6 = 6 growth months achieved), they were brought back to the experimental set-up, measured for growth and kept for 10 days in the experimental tank before dissection (Figure 1).

\subsection{Growth, meat yield rate and mortality}

Individual weight $(\mathbf{W})$ was measured at T0, T3 and T6 to estimate growth. The first growth rate $\left(\boldsymbol{G} \boldsymbol{w} \cdot \boldsymbol{m}_{0-3}\right)$ is related to the capacity for growth recovery after acute stressors, the second 
growth rate is related to the usual farm rearing conditions $\left(\boldsymbol{G w} \cdot \boldsymbol{m}_{3-\boldsymbol{6}}\right)$.

$$
\begin{aligned}
& \boldsymbol{G} \boldsymbol{w} \cdot \boldsymbol{m}_{\boldsymbol{0 - 3}}=\left(\left(\mathrm{W}_{\mathrm{T} 3}-\mathrm{W}_{\mathrm{T} 0}\right) / \mathrm{NbD}\right) * 30 \\
& \boldsymbol{G} \boldsymbol{w} \cdot \boldsymbol{m}_{\mathbf{3 - 6}}=\left(\left(\mathrm{W}_{\mathrm{T} 6}-\mathrm{W}_{\mathrm{T} 3}\right) / \mathrm{NbD}\right) * 30
\end{aligned}
$$

Where: $\mathrm{NbD}$ is the number of days in the sea-growing structure, specific for each repetition according to the date of return to the sea-growing structures.

Abalone were dissected at T6, separating the foot from the viscera, the head was also removed from the foot. The foot was weighed (Foot). All the weights presented are wet weights. The meat yield rate (FootR) was determined using the formula (Geber, 2013):

$$
\boldsymbol{F o o t} \boldsymbol{R}=\text { Foot } / \mathrm{W}_{\mathrm{T} 6}
$$

Mortalities were monitored over time. A rank variable was used with 5 modalities (SurvivalR) : 0= Abalone dead at the end of the 3-week laboratory period, $1=$ abalone dead before T3, 2=abalone dead between T3 and T6, 3=abalone dead during summer observations, $4=$ abalone alive at the end of the experiment.

\subsection{Behavioural measurement}

The videos were analysed with the software VLC mediaplayer. The movement behaviour was studied for $48 \mathrm{~h}$ over the $5^{\text {th }}$ and $6^{\text {th }}$ day of the habituation period. The total duration of movement per day (Move.D hour $^{-1}$ ) was measured. In addition, animals were attributed to one of two categories: 1 for "wanderer" with more than one hour of movement per day (which represented 50\% of the abalone) and 0 for "sedentary" if they moved less (Cenni et al., 2009).

The righting test was performed on the last day of the post-acute stress period, just after a haemolymph sampling procedure (see below). Abalones were gently placed on their back in the center of a white 12 -L bucket containing $5 \mathrm{~L}$ of sea water at the same temperature as the tanks. The righting movement latency (Rightinglatency $\cdot \mathrm{min}^{-1}$ ) was measured from the 
time of the abalone's placement in the bucket to when the abalone had fully turned over. If an abalone did not successfully turn over in a delay of 4 minutes, a latency of 4 min was recorded for this abalone.

\subsection{Phagocytosis efficiency measurement}

Haemolymph was collected on the last day of the 3-week laboratory experiment. Abalones were gently detached from the tank. Haemolymph (about $0.2 \mathrm{ml}$ per individual) was collected from the pedal sinus using $1 \mathrm{ml}$ syringes and $25 \mathrm{G} \times 1 / 2$ needles in less than $1 \mathrm{~min}$ to avoid excessive stress. It was transferred into a vial and kept on ice. Samples were treated just after collection to avoid aggregation. To measure a phagocytosis efficiency, a protocol adapted from Travers et al. (2008c) was followed. In summary, $50 \mu \mathrm{l}$ of haemolymph was deposited into a 24 -well plate containing $50 \mu \mathrm{l}$ of sterile seawater. Haemocytes were allowed to adhere for $15 \mathrm{~min}$ at $18^{\circ} \mathrm{C}$. Fluorescent beads (fluoresbrite YG Microspheres $2.00 \mu \mathrm{m}$, Plysciences, 1:100 in distilled water) were added. After $2 \mathrm{~h}$ at $18^{\circ} \mathrm{C}$, supernatants were removed and $100 \mu \mathrm{l}$ of trypsin (2.5 mg.mL-1 in AASH) was added to detach the adherent cells. Plates were shaken for $10 \mathrm{~min}$. Then $100 \mu \mathrm{l}$ of $6 \%$ formalin was used to stop the reaction. The phagocytosis efficiency (Phago, \%) was defined as the percentage of haemocytes that had engulfed 3 or more beads. The phagocytosis efficiency analyses were performed on a FACS-Calibur flow cytometer (Becton Dickinson, France) equipped with a $488 \mathrm{~nm}$ laser. Cells were counted for 60 s. Data analysis was done with WinMDI software.

\subsection{Gonadic development measurement}

Visual gonad index (VGI) was measured at T3 (VGI3m). The gonad was observed on the posterior of the ventral side, in the middle of the bilateral axis, using a modified protocol from Uki et al. (1982) (Table 1).

At T6, the gonadic tissue above the digestive gland was sliced off with a scalpel in order to 
separate the gonad from the digestive gland and weighed (Gon) A gonad weight ratio was calculated (GonR):

$$
\text { GonR= Gon } / \mathrm{W}_{\mathrm{T} 6}
$$

\subsection{Statistical analyses}

Because the Shapiro-Wilk normality test and Levene's test for homogeneity of variances could not be verified, a bivariate Wilcoxon - Mann-Whitney test was used to compare the traits of the wild and farm populations. Because no difference was observed for most of the variables, data from wild and farm population were pooled for subsequent analysis (PCA and variation coefficient).

In order to compare the different quantitative traits, the mean and the coefficient of variation (standard error divided by the mean) were calculated.

Statistical analyses were performed with R 3.0.3 software, using the FactoMineR package to plot the principal component (PCA) output (Lé et al., 2008). All the variables were reduced and scaled before the implementation for the two PCA models. A regularized iterative imputation was performed with the package missMDA for missing data, representing $8 \%$ of the data (Josse et al., 2013). Iterative imputation can create false correlations in the dataset. To reduce this risk, the recommended methodology of Quinn and Keough (2002) was followed.

For the PCA performed on mortality, the complete data set was used with 120 individuals. The second PCA model performed on growth and dissection was implemented on the 43 individuals that survived after the 6 month experiment.

The PCA scores on the first and second component were recorded for all abalone and an ANOVA test was performed on the score in the PCA components to study the differences between origin (wild/farm) of the abalone. To control the meaning of relationships observed 
between two related traits in the PCA, a linear model was performed on the original dataset $(n=120)$ after a verification of the residual normality. 


\section{Results}

\subsection{Comparison between wild and farmed abalone}

There were significant differences in total duration of movement per day and righting movement latency between wild and farmed abalone $(\mathrm{P}<0.001)$ : wild abalone moved on average 2.1 hours per day while farm abalone moved for 1.1 hour. Wild abalone took more time to do their righting movement than farmed ones $(\mathrm{P}<0.001)$. No differences were observed between wild and farmed abalone for the other traits (Table 2).

The 3-week stress period resulted in a cumulative mortality of $45 \%$ at three months and $77 \%$ at six months. The two stocks had the same mortality profile during the experiment (Figure 2).

\subsection{Screening summary}

Because no difference was observed for most of the variables, it was decided to present the screening summary as one set of data. The abalone moved on average for $6 \%$ of the day: $16 \%$ of the abalone did not move at all and $35 \%$ of the population moved for less than one hour per day while the other $49 \%$ moved on average for 2.5 hours per day (Figure 3).

The mean and coefficient of variation were calculated for each quantitative trait in order to determine the variability of a trait in the population studied (Table 2). The growth variables were the two most variable traits, followed by behavioural traits. The phagocytosis efficiency and dissection traits were the least variable (Table 2).

\subsection{Relationships of traits with later survival in sea cages}

A PCA model was performed with the variables recorded during the physiological and behavioural tests in winter and the survival rank during the next five months (Figure 4). The 
first three components of the PCA explained $71 \%$ of the total variance (29\% for the first component, $23 \%$ for the second component and $19 \%$ for the third component) (Figure 4). The most important loadings on the first component were the phagocytosis efficiency (Phago, $\cos ^{2}$ $=0.53)$, the initial weight $\left(\boldsymbol{W T O}, \cos ^{2}=0.43\right)$ and the duration of movement $\left(\right.$ Move. $\boldsymbol{D}, \cos ^{2}=$ 0.46). This component may represent the immune and activity traits. The most important loadings on the second component were the latency of success in the turn over test (Righting.latency, $\cos ^{2}=0.66$ ) and the survival rank of an abalone (SurvivalR, $\cos ^{2}=0.30$ ). Abalone which had difficulties in turning over after the stress exposure were the quickest to die during the next 6 months. This component may indicate survival is associated with the energy level at the end of the stress period. Wild abalone had a higher average individual loading in the second component than farm abalone (ANOVA, $\mathrm{P}<0.05$ ) (Figure 5). Wild abalone has in average a lower survival rank and a higher righting latency.

Phagocytosis efficiency and survival are not related in our data set. The map of individuals (Figure 5) shows no clear discrimination between wild and farmed abalone based on these variables.

\subsection{Relationship of traits with later growth in sea cages}

A PCA model was performed on the 43 individuals who survived using the variables recorded during the physiological and behavioural tests in winter, the growth rates measured three months and 6 months after the winter stress period, and the dissection traits. The first three components of the PCA explained $61 \%$ of the total variance in the data set (27\% for the first component, $22 \%$ for the second component and $11 \%$ for the third component) (Figure 6 ). The most important loadings on the first component were the growth in weight during the first three months of rearing $\left(\boldsymbol{G} \boldsymbol{w} \cdot \boldsymbol{m}_{\boldsymbol{0 - 3}}, \cos ^{2}=0.58\right)$, the initial weight $\left(\boldsymbol{W T O}, \cos ^{2}=0.63\right)$ and the movement duration per day (Move.D, $\left.\cos ^{2}=0.32\right)$. The abalone with the highest growth in weight during the three months following the stress period were the ones characterized by a 
longer movement duration during the behavioural observation. This may represent an association between growth and movement traits. The most important loadings on the second component of the PCA model were the gonad weight ratio six months after the stress period $\left(\boldsymbol{G o n R}, \cos ^{2}=0.54\right)$, the visual gonad index three months after the stress period $\left(\boldsymbol{V G I 3 m}, \cos ^{2}\right.$ $=0.39)$, the phagocytosis efficiency at the end of the stress period $\left(\boldsymbol{P h a g o}, \cos ^{2}=0.39\right)$ and the growth between three and six months after the stress period $\left(\boldsymbol{G w} \cdot \boldsymbol{m}_{\mathbf{0 - 3}}, \cos ^{2}=0.24\right)$. This represents an association between immune competence, spring early gonad development, summer gonad maturity and summer growth.

\subsection{Quantitative assesment of phenotypic relationships}

The correlation between survival rank (SurvivalR) and righting latency (Righting.latency) was not significant. The linear model applied to the traits associated with later growth in the sea cages showed that the righting latency (Righting.latency) and the total movement duration per day (Move) were correlated with the growth rate in weight during the spring $\left(\boldsymbol{G w} . \boldsymbol{m}_{0-3}\right)$ (respectively, $\mathrm{P}<0.02$ and $\left.\mathrm{P}<0.05\right)$. These two variables explained $11 \%$ of the total spring growth variance. The visual gonad index (VGI3m) was negatively correlated with the growth in the summer $(\mathrm{P}<0.02)$ and a tendency existed between this summer growth and the gonad mass ratio $(\boldsymbol{G o n R})$ at the end of the experiment $(\mathrm{P}=0.057)$. These two variables together explained $15 \%$ of the total summer growth variance. 


\section{Discussion}

The mean values obtained for important traits (phagocytosis efficiency, gonad weigh ratio, meat yield rate) are close to those found in similar situations in Haliotis tuberculata (Basuyaux, 2000; Basuyaux et al., 1998; Travers et al., 2008b). However, the variance is high for several traits. The two growth traits present the highest variability, which could indicate there is a high potential gain for a future selective process, as has been the case for other abalones in the world (Elliott, 2000). Movement behaviour is another trait characterized by a high variability. In contrast, phagocytosis presented relatively little variation. The low variability observed may indicate that the selective pressure is high on this trait because it is related to disease susceptibility (Travers et al., 2008a) and to others important parameters such as acquisition and transportation of nutrients and metabolites, and elimination / reparation of tissues.

Farm and wild abalone exposed to farm stressors could only be discriminated with two behavioural traits, suggesting that abalone are at the very beginning of their domestication process in the studied farm stock. Consistent behavioural changes are expected to be some of the first changes linked to culture condition responses (Huntingford, 2004). This is associated with the 'domestication syndrome' with a change in resource allocation towards growth and reproduction and away from predator avoidance and foraging activity, important in complex natural environments (Lorenzen et al., 2012; Thorpe, 2004). Wild abalone spent more time moving during the night period at the end of the habituation period and took more time to turn themselves over in the test at the end of the 3-week experimental period, before returning to sea-structure. This increased movement could be linked to a higher stress response to the new environment (Robinson et al., 2013). Movement in control situations can also be an indicator 
of foraging motivation. Wild abalone might be motivated to gain food either due to an active strategy of foraging, as is often observed in wild individuals in contrast to domesticated ones (Gustafsson et al., 1999). This difference can also result from an effect of reduced glucose level associated with hunger, leading to increased foraging activity (Carefoot et al., 1993). A scale of six levels of domestication can be used to classify the domestication rank of reared fish versus wild animals (Teletchea and Fontaine, 2014). Because farmed abalone were obtained with wild progenitors, they only reach the third level of the domestication process on this scale. In other words, these farm abalone can be considered as "captive types" (Lorenzen et al., 2012) with domestication dominated by inadvertent responses to the culture conditions. Genetic changes are probably small due to the constant use of wild progenitors while alteration of development is probably the most important mechanism of domestication at that stage. This result has justified the production of a PCA model with the two populations pooled. Indeed, in the first PCA model, wild and farm stocks could not be discriminated. However different loadings for wild and farm stocks were obtained in the second component indicating that wild abalone moved twice as much and needed twice as much time to turn over than the farm abalone.

A high mortality rate (45\%) was observed in the first 3 months of the recovery period after the stress procedure. Wild and farmed abalone had the same cumulative mortality profile and no significant differences in survival rank were reported. Abalone are sensitive to farm stressors (Hooper et al., 2007; Travers, 2008) with high mortalities regularly observed following farm procedures. The stressors applied in this study are commonly encountered by abalone during farm processes. In addition, haemolymph sampling probably added a supplementary acute stress, strengthening these effects. Mortality is often observed after highdensity condition exposure (Huchette et al., 2003; Travers et al., 2010), moving to a new 
environment and handling (Hooper et al., 2011; Ragg et al., 2000), and shaking (Malham et al., 2003). A rate of $45 \%$ mortality after normal aquaculture procedures also shows that European abalone is at the really early stage of his domestication process.

The probability of survival of abalone was related to the time to right themselves. In the literature, the righting test has been shown to be a good indicator to measure the metabolic capacity of an abalone (Baldwin et al., 2007). This result might indicate that after three weeks of stress, abalone able to right themselves quickly in winter have a good energetic reserve and thus would be resistant to stressors and survive in the rearing process. The righting capacity may be a good proxy of stress resilience. The fact that there was no significant correlation between righting time and survival rank could be explained by the fact that this variable had only 5 ranks. It is possible that with a more precise measure of the mortality a better correlation would have been found. In addition, this test should be interpreted with some care in the context of our experiment. It was performed just after haemolymph sampling, which represent an acute stress. It represents an integrative proxy of the 3-week procedure and acute sampling stress procedure, before returning to sea-structure.

The phagocytosis rate after one week of stress recovery was unexpectedly not related to survival over a long period. This result is in contradiction with several results reported in the literature: phagocytosis depression was reported to be linked to increased mortality (Hooper et al., 2011; Hooper et al., 2014; Travers et al., 2009). A decrease of phagocytosis efficiency has often been reported one hour after the application of a stressor (Cheng et al., 2004b; Hooper et al., 2011; Malham et al., 2003). This may be followed by an increase of phagocytosis efficiency above the basal level before it returns to the initial level within in a day after a shaking stress (Malham et al., 2003; Travers et al., 2009). In our case, the phagocytosis rate can be considered as a measure of the result of three weeks of important 
chronic and acute stress. It might reflect only the chronic stimulation of the immune system by stressors over this period, rather than a short term elevation above the basal level.

In the first three months of rearing in the farm structures, most of the abalone which had survived lost weight. This might be an indication of the mobilization of their foot reserves during the stress procedures. A loss in weight after a manipulation and fishing is usually observed for abalone (Gorfine, 2000; Ragg et al., 2000). It can still be observed 50 days after the manipulation (Day and Fleming, 1992). In this study, growth in weight in the first three months can be considered as a variable that indicates recovery capacity after the application of acute stressors. The growth observed the next three months indicates a complete stress recovery and corresponds to normal growth for mature adult $H$. tuberculata (Basuyaux, 1997).

Growth variables were positively related to the duration of movement per day observed in winter in the laboratory. To our knowledge, no previous studies have looked at the relationships between growth and daily activity in abalone. Two kinds of movement strategy have been observed in abalone. Some abalone stay in the same place and behave as "sedentary" while others move more frequently and behave as "wanderers" (Cenni et al., 2009). Here no clear categories were found. More than $50 \%$ did not move at all or moved for less than one hour per day. Thus it seems inappropriate to classify the population as wanderer / sedentary. High variability of movement was present in our experiment. More active abalone during the habituation period had a higher growth rate during the subsequent 6-month period. These animals might access more of the food in a cage and thus have better growth than more sedentary abalone. Another hypothesis is that abalone that were highly motivated for food moved more to get this food. Even if locomotion represents an important metabolic cost, adhering to the substratum appears to be costly as well (Donovan and Carefoot, 1998). Thus 
greater activity of abalone could signal that active abalone will be more valuable to the farm rearing, although the superiority of their trophic efficiency still needs to be studied. The hypothesis of a relationship between growth and the quantity of movement observed is supported by the fact that the offspring of animals selected on the basis of better growth seem to move more (Robinson et al., 2013). In this study no feeding behaviour was observed during the $48 \mathrm{~h}$ observation, probably due the low winter temperature. A longer observation period or an analysis performed in spring or summer time might be more appropriate to study the exact relationship between activity strategy, feeding behaviour, feeding efficiency and growth.

Another behavioural variable, the time taken to right themselves after the 3 weeks of stress, was associated with a better growth during the first 3 months. As described above, the quickest abalone to right themselves were probably the abalone with the highest energy level and these were more able to resist the stress procedures (Baldwin et al., 2007).

A relation was observed between gonad development and the growth over 3-months in summer: animals which had the greatest gonad development were those with the lowest growth. This result is expected, as mature abalone allocate energy to gonad development, with a concurrent reduction of growth (Bilbao et al., 2012; Roussel et al., 2011). In addition, a positive relationship was observed between the visual gonad index (VGI) measured at the end of the spring and the weight of the gonad during summer. The early onset of gonad development is also probably linked with the intensity of energy allocation to the gonad during the summer. VGI may be a useful non-invasive measurement of $H$. tuberculata maturation (Uki, 1982). It was found that mature abalone allocate $40 \%$ of their energy to gonad development, which may involve a high economic loss if the foot is the only part of the 
abalone sold (Peck et al., 1987). In order to boost the production of larger abalone, selecting abalone with delayed maturation and reduced VGI might be a useful selection strategy.

The analysis of the relationship between the growth, physiological and behavioural characteristics was performed only on the surviving abalone. This might have biased the results. However, the coherence of the relationship observed between phagocytosis efficiency and duration of movement in the two PCA models indicates that if a bias exists, it is relatively low. The initial weight was controlled at the beginning of the experiment but some differences remained between individuals. This variable was included in the analysis in order to test if bigger animals were also more mature, but this was not the case in this study.

\section{Conclusion}

The relationships of 10 behavioural and physiological variables with survival and weight gain after application of important stressors were studied in order to provide a better understanding of Haliotis tuberculata biology during early domestication stage. After a period of stress, the capacity of an abalone to perform a righting movement was shown to be linked to better survival and was related to a smaller loss in weight during the recovery period. This test could be used to assess the resiliency of an abalone to farm stressors. Greater movement of abalone in winter was also linked with better growth. Active abalone may be more able to access the food in sea rearing structures. Even if the heritability of behavioural traits is commonly low, they were reported to be significantly different from 0 for australian abalone farmed stock (Robinson et al., 2013). Behavioural traits could be used in a selective breeding plan in addition to production traits. Moreover, important individual variability was observed in this study which might indicate potential improvement if a selection process using these traits was implemented (Cenni et al., 2009). 


\section{Acknowledgements}

The authors would like to thank the team of France Haliotis, Xavier Lesage, Frederic Laurans, Mickael Gleeson, Iain McKensy, and Maryvonne Leroux for the provision and the care of the animals, and the assistance during the experiment.

In addition, they would like to thank the LEMAR diving team for collecting wild abalone in difficult winter conditions.

Thanks to Prof Mick Keough who helped with the analysis.

This work was conducted in the context of a $\mathrm{PhD}$ partially funded by France Haliotis and ANRT (CIFRE N²014 0643) 


\section{$\underline{\text { References }}$}

Allen, V., Marsden, I., Ragg, N., Gieseg, S., 2006. The effects of tactile stimulants on feeding, growth, behaviour, and meat quality of cultured Blackfoot abalone, Haliotis iris. Aquaculture. 257, 294-308.

Baldwin, J., Elias, J.P., Wells, R.M.G., Donovan, D.A., 2007. Energy metabolism in the tropical abalone, Haliotis asinina Linné: Comparisons with temperate abalone species. J. Exp. Mar. Biol. Ecol. 342, 213-225.

Basuyaux, O., 1997. Etude et modélisation des paramètres physico-chimiques sur la croissance de l'ormeau (Haliotis tuberculata) en élevage en circuit semi fermé, Syndicat mixte de l'équipement du Littoral. Université de Caen Basse Normandie, pp. 239.

Basuyaux, O., 2000. Growth rate of the European abalone, Haliotis tuberculata, fed an artificial diet (Adam \& Amos) and macroalgae. Retrieved from http://www.adamamos.com/olivier_basuyaux.htm on 15/09/2014

Basuyaux, O., Mathieu, M., Day, C., 1998. Effects of salinity on diet and growth of the sea urchin Paracentrotus lividus and the abalone Haliotis tuberculata. Bulletin De La Societe Zoologique De France. 123, 141-150.

Bilbao, A., Uriarte, I., Viera, M.D., Sosa, B., Fernandez-Palacios, H., Hernandez-Cruz, C.M., 2012. Effect of macroalgae protein levels on some reproductive aspects and physiological parameters for the abalone, Haliotis tuberculata coccinea (Reeve 1846). J. World Aquacult. Soc. 43, 764-777. 
Camara, M.D., Symonds, J.E., 2014. Genetic improvement of New Zealand aquaculture species: programmes, progress and prospects. N. Z. J. Mar. Freshw. Res. 48, 466-491.

Carefoot, T.H., Qian, P.Y., Taylor, B.E., West, T., Osborne, J., 1993. Effect of starvation on energy reserves and metabolomism in the northern abalone, Haliotis-kamtschatkana. Aquaculture. 118, 315-325.

Cenni, F., Parisi, G., Gherardi, F., 2009. Use of space and costs/benefits of locomotion strategies in the abalone, Haliotis tuberculata. Ethol. Ecol. Evol. 21, 15-26.

Cenni, F., Parisi, G., Scapini, F., Gherardi, F., 2010. Sheltering behavior of the abalone, Haliotis tuberculata L., in artificial and natural seawater: The role of calcium. Aquaculture. 299, 67-72.

Cheng, W., Hsiao, I.S., Chen, J.C., 2004a. Effect of ammonia on the immune response of Taiwan abalone Haliotis diversicolor supertexta and its susceptibility to Vibrio parahaemolyticus. Fish Shellfish Immunol. 17, 193-202.

Cheng, W., Hsiao, I.S., Hsu, C.H., Chen, J.C., 2004b. Change in water temperature on the immune response of Taiwan abalone Haliotis diversicolor supertexta and its susceptibility to Vibrio parahaemolyticus. Fish Shellfish Immunol. 17, 235-243.

Claireaux, G., McKenzie, D.J., Genge, A.G., Chatelier, A., Aubin, J., Farrell, A.P., 2015. Linking swimming performance, cardiac pumping ability and cardiac anatomy in rainbow trout. J Exp Biol. 208, 1775-1784.

Day, R.W., Fleming, A.E., 1992. The determinants and measurement of abalone growth. in: Shepherd, S.A., Tegner, M.J., Guzman Del Proo, S.A. (Eds.), Abalone of the world: biology, fisheries and culture. Fishing News Books, Oxford, pp. 141-168.

Donovan, D.A., Carefoot, T.H., 1998. Effect of activity on energy allocation in the northern abalone, Haliotis kamtschatkana (Jonas). J. Shellfish Res. 17, 729-736. 
Elliott, N., 2008. Abalone genetic research: Australian review and prospects. J. Shellfish Res. $27,1005-1005$.

Elliott, N.G., 2000. Genetic improvement programmes in abalone: what is the future? Aquac. Res. 31, 51-59.

Geber, M.E., 2013. Quantitative assessment of yield traits between family groups of the cultured abalone, Haliotis midae, during the process of canning University of Stellenbosch. , pp. 74

Gordon, H.R., Cook, P.A., 2004. World abalone fisheries and aquaculture update: Supply and market dynamics. J. Shellfish Res. 23, 935-939.

Gorfine, H.K., 2000. Post harvest weight loss has important implications for abalone quota management. J. Shellfish Res. 19, 515.

Gustafsson, M., Jensen, P., de Jonge, F.H., Illmann, G., Spinka, M., 1999. Maternal behaviour of domestic sows and crosses between domestic sows and wild boar. Appl. Anim. Behav. Sci. 65, 29-42.

Hooper, C., Day, R., Slocombe, R., Handlinger, J., Benkendorff, K., 2007. Stress and immune responses in abalone: Limitations in current knowledge and investigative methods based on other models. Fish Shellfish Immunol. 22, 363-379.

Hooper, C., Day, R., Slocombe, R., Benkendorff, K., Handlinger, J., 2011. Effect of movement stress on immune function in farmed Australian abalone (hybrid Haliotis laevigata and Haliotis rubra). Aquaculture. 315, 348-354.

Hooper, C., Day, R., Slocombe, R., Benkendorff, K., Handlinger, J., Goulias, J., 2014. Effects of severe heat stress on immune function, biochemistry and histopathology in farmed Australian abalone (hybrid Haliotis laevigata x Haliotis rubra). Aquaculture. 432, 2637. 
Huchette, S.M.H., Clavier, J., 2004. Status of the ormer (Haliotis tuberculata L.) industry in Europe. J. Shellfish Res. 23, 951-955.

Huchette, S.M.H., Koh, C.S., Day, R.W., 2003. Growth of juvenile blacklip abalone (Haliotis rubra) in aquaculture tanks: effects of density and ammonia. Aquaculture. 219, 457470.

Huntingford, F.A., 2004. Implications of domestication and rearing conditions for the behaviour of cultivated fishes. J. Fish Biol. 65, 122-142.

Josse, J., Timmerman, M., Kiers, H.A., 2013. Missing values in multi-level simultaneous component analysis. Chemometr. Intell. Lab. 129, 21-32.

Lé, S., Josse, J., Husson, F., 2008. FactoMineR: An R Package for Multivariate Analysis. J. Stat. Softw. 25, 18.

Lorenzen, K., Beveridge, M.C.M., Mangel, M., 2012. Cultured fish: integrative biology and management of domestication and interactions with wild fish. Biol. rev. 87, 639-660.

Lucas, T., Macbeth, M., Degnan, S.M., Knibb, W., Degnan, B.M., 2006. Heritability estimates for growth in the tropical abalone Haliotis asinina using microsatellites to assign parentage. Aquaculture. 259, 146-152.

Malham, S.K., Lacoste, A., Gelebart, F., Cueff, A., Poulet, S.A., 2003. Evidence for a direct link between stress and immunity in the mollusc Haliotis tuberculata. J. exp. zool. Part. A. 295A, 136-144.

Millot, S., Péan, S., Leguay, S., Vergnet, A., Chatain, B., Bégou, M.-L., 2010. Evaluation of behavioral changes induced by a first step of domestication or selection for growth in the European sea bass (Dicentrarchus labrax): A self-feeding approach under repeated acute stress. Aquaculture. 306, 221-217.

Monget, P., Le Bail, P.-Y., 2009. Le phénotypage des animaux : le nouveau défi ? Renc. Rech. Ruminants. 16, 407-409. 
Peck, L.S., Culley, M.B., Helm, M.M., 1987. A laboratory energy budget for this ormer Haliotis tuberculata. J. Exp. Mar. Biol. Ecol. 106, 103-123.

Price, E.O., 1984. Animal domestication and behavior, CABI publishing ed.

Quinn. G, Keough. M, 2002. Experimental Design and Data Analysis for Biologists.

Ragg, N.L.C., Taylor, H.H., Behrens, J., 2000. Stress and weight loss associated with handling in the blackfoot abalone, Haliotis iris. J. Shellfish Res. 19, 528-529.

Rauw, W.M., Kanis, E., Noordhuizen-Stassen, E.N., Grommers, F.J., 1998. Undesirable side effects of selection for high production efficiency in farm animals: a review. Livest. Prod. Sci. 56, 15-33.

Rhode, C., Hepple, J.A., Jansen, S., Davis, T., Vervalle, J., Bester-van der Merwe, A.E., Roodt-Wilding, R., 2012. A population genetic analysis of abalone domestication events in South Africa: Implications for the management of the abalone resource. Aquaculture. 356, 235-242.

Robinson, N., Smith, B., Cooke, I., Strugnell, J., 2013. A snail's pace: A preliminary analysis of the effects of stress and genetics on movement of Haliotis. Aquaculture. 376, 25-35.

Roussel, S., Huchette, S., Clavier, J., Chauvaud, L., 2011. Growth of the Europeen abalone (Haliotis tuberculata L.) in stu: Seasonality and ageing using stable oxygen isotopes J. Sea Res. 65, 213-218.

Shepherd, S.A., and Cannon, J., 1988. Studies on southern Australian abalone (genus Haliotis) X. Food and feeding in juveniles. J. Malac. Soc. Aust. 9, 21-26.

Teletchea, F., Fontaine, P., 2014. Levels of domestication in fish: implications for the sustainable future of aquaculture. Fish. Fish. 15, 181-195.

Thorpe, N., 2004. European prehistory: a survey. Antiquity. 78, 944-945. 
Travers, M.A., 2008. Interaction de la bactérie Vibrio harveyi avec son hôte, l'ormeau Haliotis tuberculata : approches physiologiques, cellulaires et moléculaires. Université de Bretagne Occidental.

Travers, M.A., Le Goïc, N., Huchette, S., Koken, M., Paillard, C., 2008a. Evidence of an immune depression in spawning period, at the basis of Haliotis tuberculata susceptibility to the pathogen Vibrio harvey. Fish and Shellfish Immunology. 25, 800808.

Travers, M.A., Le Goic, N., Huchette, S., Koken, M., Paillard, C., 2008b. Summer immune depression associated with increased susceptibility of the European abalone, Haliotis tuberculata to Vibrio harveyi infection. Fish Shellfish Immunol. 25, 800-808.

Travers, M.A., Basuyaux, O., Le Goic, N., Huchette, S., Nicolas, J.L., Koken, M., Paillard, C., 2009. Influence of temperature and spawning effort on Haliotis tuberculata mortalities caused by Vibrio harveyi: an example of emerging vibriosis linked to global warming. Global Change Biol. 15, 1365-1376.

Travers, M.A., Meistertzheim, A.L., Cardinaud, M., Friedman, C.S., Huchette, S., Moraga, D., Paillard, C., 2010. Gene expression patterns of abalone, Haliotis tuberculata, during successive infections by the pathogen Vibrio harveyi. J. Invertebr. Pathol. 105, 289-297.

Travers, M.A., da Silva, P.M., Le Goic, N., Marie, D., Donval, A., Huchette, S., Koken, M., Paillard, C., 2008c. Morphologic, cytometric and functional characterisation of abalone (Haliotis tuberculata) haemocytes. Fish Shellfish Immunol. 24, 400-411.

Uki, N., and Kikuchi, S., 1982. Influence of food levels on maturation and spawning of the abalone, Haliotis discus hannai related to effective accumulative temperature. Bull. Tohoku Reg. Fish. Res. Lab. 45, 45-53. 


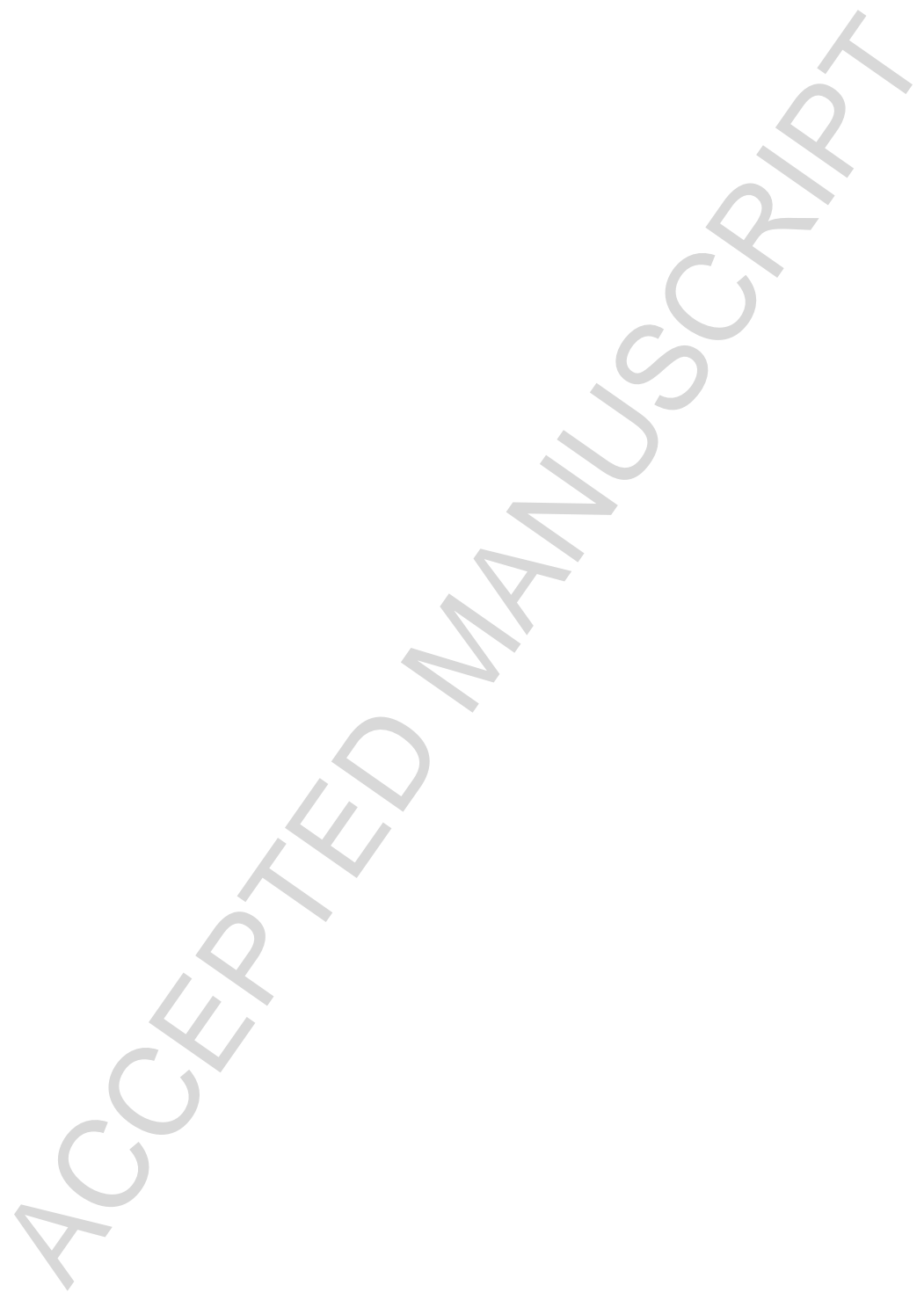




\section{Figure 1:}

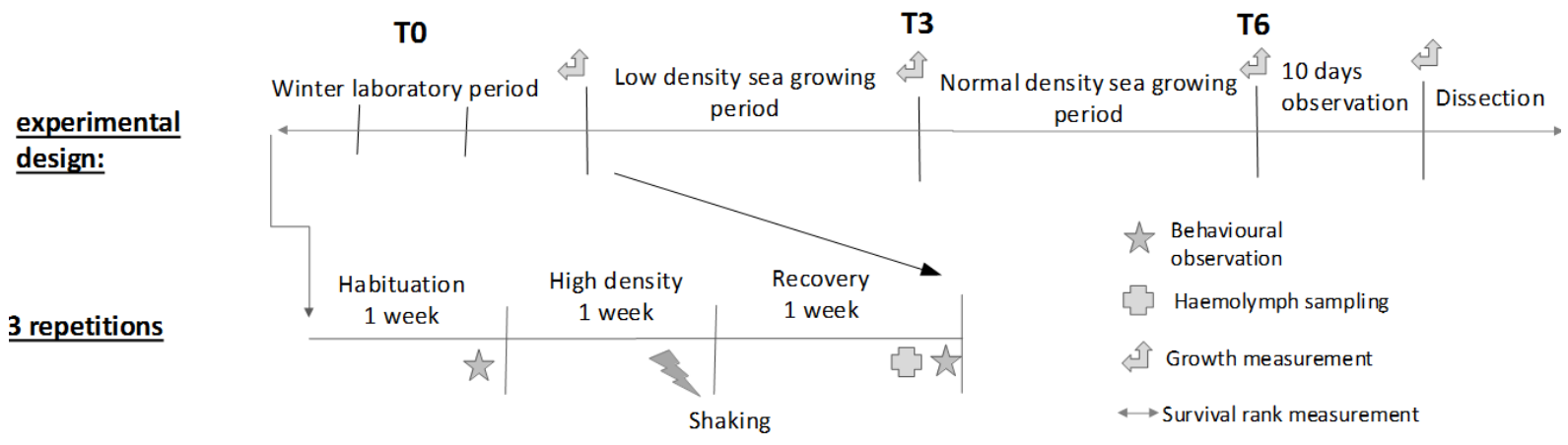


Figure 2:

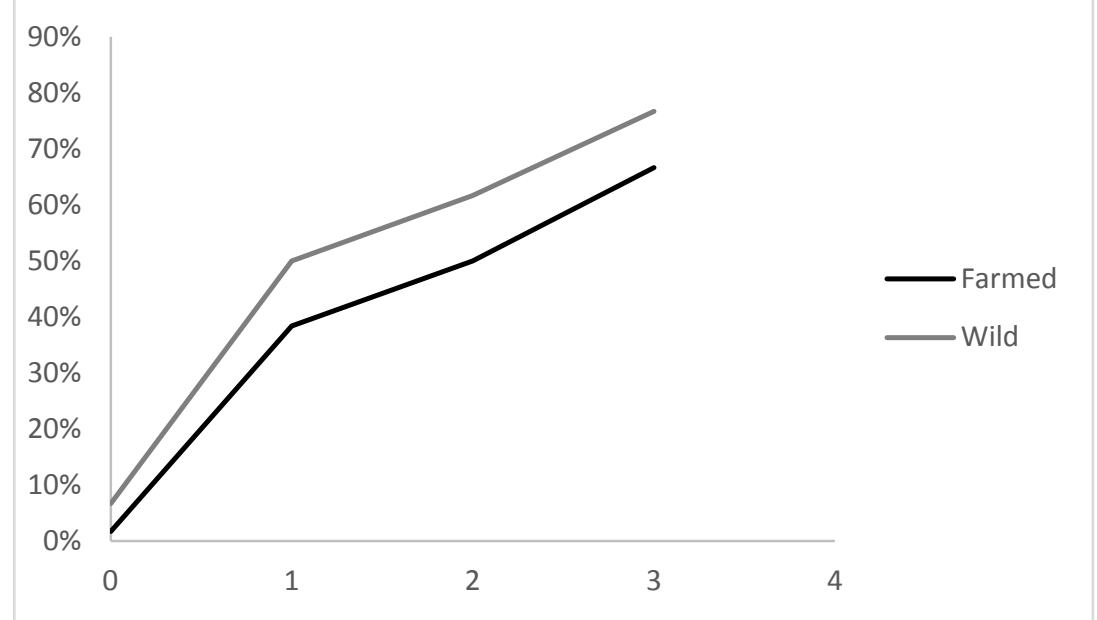


Figure 3

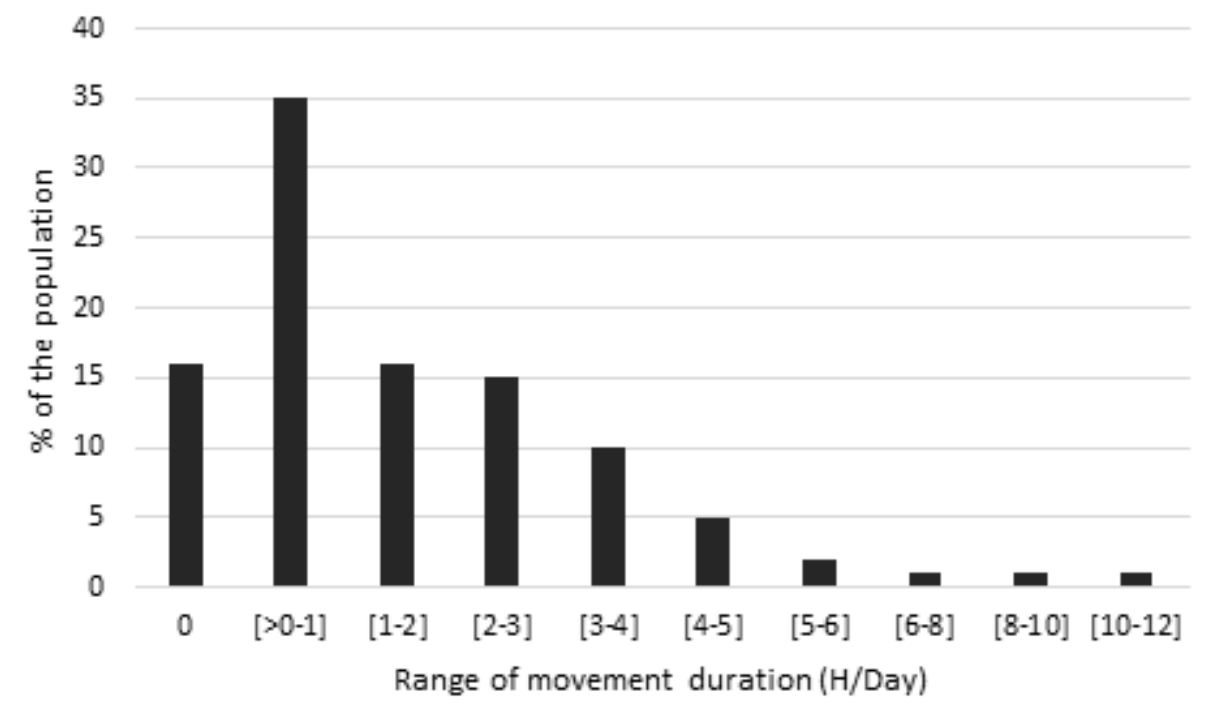


Figure 4:

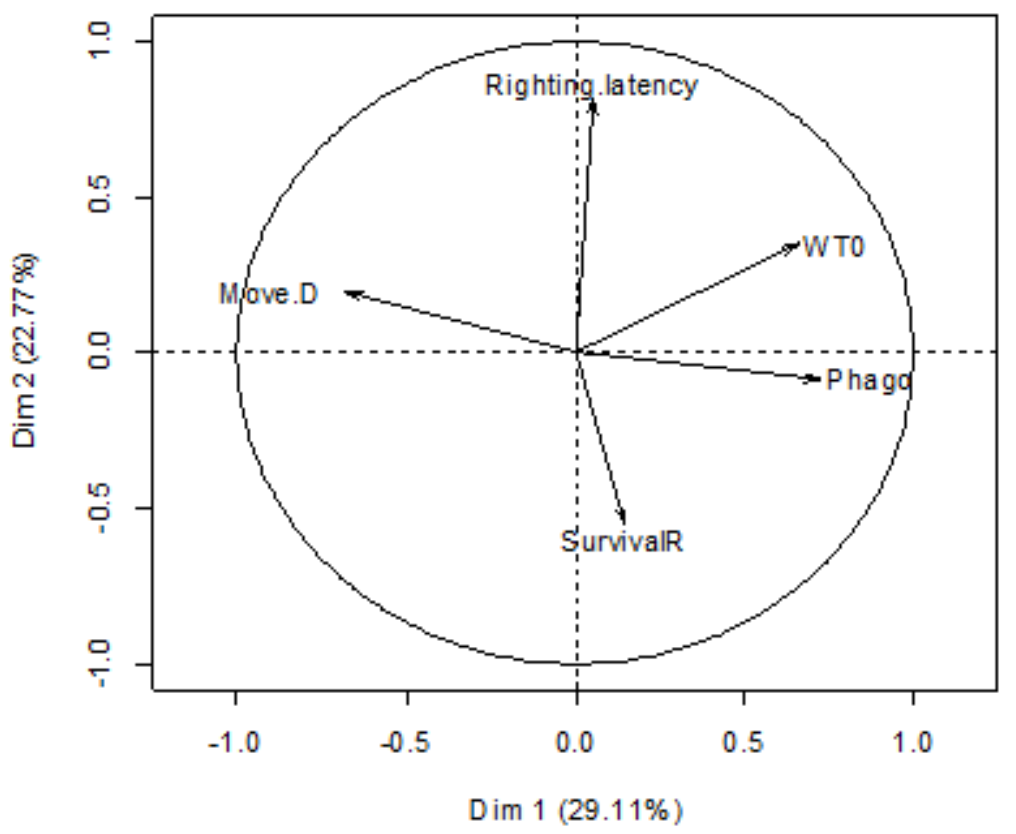


Figure 5:

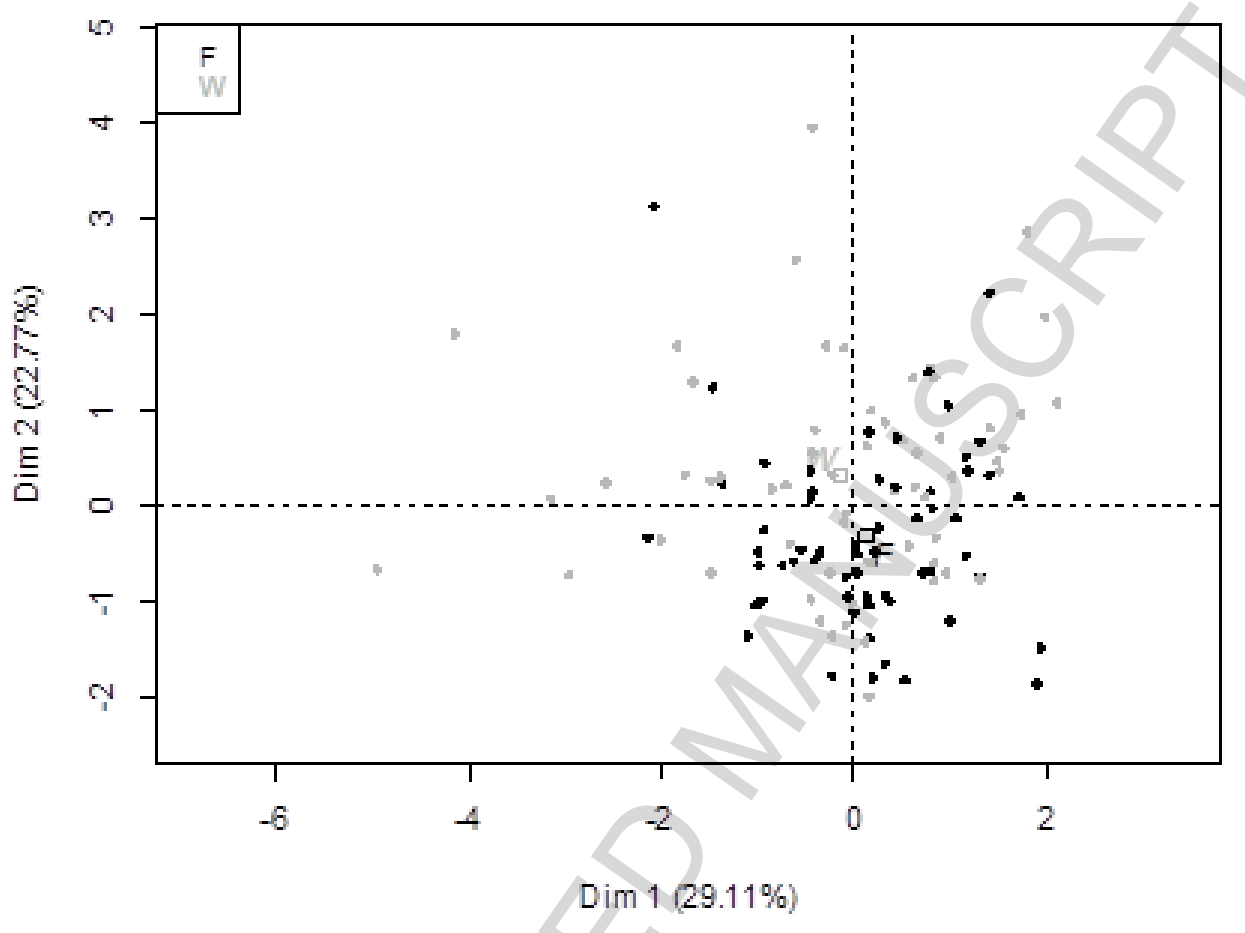


Figure 6:

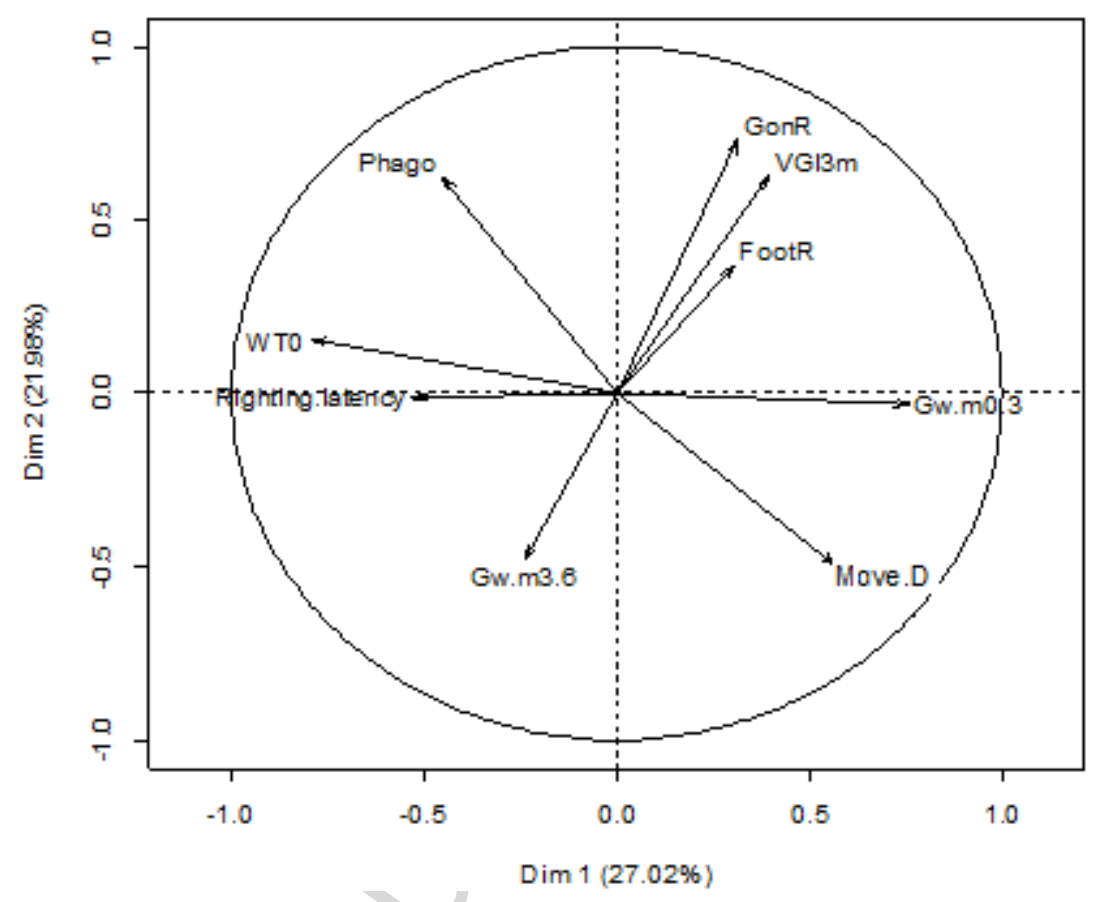




\section{Figures Titles}

Figure 1: Details of the experimental procedure during the laboratory period and sea growing period. The variables measured and used in the analysis are listed.

Figure 2: Cumulative mortality in $\%$ for the two stocks during the experiment

Figure 3: The distribution of total duration of movement per day in the population $(n=120)$

Figure 4: Principal component analysis (PCA) plot of selected phenotypic parameters in relation to survival $(\mathrm{n}=120)$ : SurvivalR $=$ survival rank, Move. $\boldsymbol{D}=$ average duration of movement per day, $\boldsymbol{W T} \mathbf{0}=$ Weight at the beginning of the experiment, Righting latency $=$ Time to realize a righting movement, Phago $=$ Phagocytosis efficiency at the end of the stress period.

Figure 5: Map of individual abalone in relation to the first two principal components. Wild abalone: grey dots; farmed abalone: black dots

Figure 6: Principal component analysis plot of selected phenotypic parameters: Phago= phagocytosis efficiency at the end of the stress period, $\boldsymbol{G o n R}=$ The gonad weight ratio at T6, $\boldsymbol{V G I 3 m}=$ Visual gonad index at T3, Foot $R=$ Foot weight ratio, $\boldsymbol{G} \boldsymbol{w} \cdot \boldsymbol{m}_{\mathbf{0 - 3}}=$ Growth in weight per month between T0 and T3. $\boldsymbol{G} \boldsymbol{w} \cdot \boldsymbol{m}_{3-\boldsymbol{6}}=$ Growth in weight per month between T3 and T6, , Move. $\boldsymbol{D}=$ total duration of movement per day, Righting time $=$ Time needed for abalone to turn themselves over at the end of the stress period, $\boldsymbol{W T} \boldsymbol{0}=$ Weight at the beginning of the experiment. 
Table 1: Visual gonad index (VGI3m) measured on the posterior of the ventral side in the middle of the bilateral axes. Adapted from Uki et al. (1982)

\begin{tabular}{cl}
\hline Value of & Citeria description \\
VGI & No gonad can be observed on the digestive gland. The sex \\
0 & Gonad is observable but flat \\
1 & Gonad is inflated and reach the level of the shell \\
3 & Gonad is developed above the level of the shell \\
4 & Gonad is observable without removing the foot of the \\
& abalone
\end{tabular}


Table 2: Mean ( \pm s.e.m), and coefficient of variation of all the quantitative variables recorded in the study for the two stocks

\begin{tabular}{|c|c|c|c|c|c|}
\hline Variables & $\begin{array}{l}\mathrm{n} \text { (wild - } \\
\text { farmed) }\end{array}$ & Wild & Farmed & $\begin{array}{l}\text { Coefficient of } \\
\text { Variation (all } \\
\text { abalone) }\end{array}$ & Origin effect \\
\hline \multicolumn{6}{|l|}{ Laboratory measurements } \\
\hline Weight at $\mathrm{T} 0(\mathrm{~g})$ & $60-60$ & $49.5 \pm 1.57$ & $48.7 \pm 0.85$ & 0.2 & NS \\
\hline Righting movement latency ( min) & $53-57$ & $1.3 \pm 0.06$ & $1.0 \pm 0.05$ & 0.7 & $\mathrm{P}<0.001$ \\
\hline $\begin{array}{l}\text { Total duration of movement per } \\
\text { day (h/day) }\end{array}$ & $60-60$ & $2.1 \pm 0.20$ & $1 \pm 0.13$ & 1.0 & $\mathrm{P}<0.001$ \\
\hline Phagocytosis efficiency $(\%)$ & $50-48$ & $24.2 \pm 0.92$ & $26.3 \pm 0.78$ & 0.8 & NS \\
\hline \multicolumn{6}{|c|}{3 and 6-month period measurements } \\
\hline Survival rank & $60-60$ & $2.1 \pm 0.12$ & $2.4 \pm 0.12$ & 0.5 & NS \\
\hline Visual gonad index at T3 & $30-42$ & $1.4 \pm 0.72$ & $1.7 \pm 0,67$ & 0.4 & NS \\
\hline $\begin{array}{l}\text { Gonad weight ratio (\% of the total } \\
\text { wet body mass) }\end{array}$ & $18-26$ & $7.0 \pm 2.03$ & $8.9 \pm 1.86$ & 7.3 & NS \\
\hline $\begin{array}{l}\text { Meat yield rate (\% of the total wet } \\
\text { body mass) }\end{array}$ & $18-26$ & $30,2 \pm 2.15$ & $34,3 \pm 3.36$ & 3.9 & NS \\
\hline $\begin{array}{l}\text { Growth ratebetween } \mathrm{T} 0 \text { and } \mathrm{T} 3 \\
\text { (g.month) }\end{array}$ & $30-42$ & & $-0.8 \pm 0.10$ & 1.4 & Ns \\
\hline $\begin{array}{l}\text { Growth rate between } \mathrm{T} 3 \text { and } \mathrm{T} 6 \\
\text { (g.month) }\end{array}$ & & & $0.7 \pm 0.11$ & 1.6 & NS \\
\hline
\end{tabular}

